\title{
QUANDO NOS LEVANTAMOS (2017) E A LUTA NO COMBATE À HOMOFOBIA
}

\author{
E. J. S. A. HONORATO ${ }^{1}$, A. C. DE A. AMAZONAS ${ }^{2}$, H. B. B. SENNA 3 , T. A. DA SILVA ${ }^{4}$, S. M. LEMOS 5 , D. S. \\ FERREIRA $^{6}$ \\ Universidade do Estado do Amazonas \\ eduhonorato@hotmail.com ${ }^{1}$
}

Artigo submetido em 05/10/2017 e aceito em 17/02/2020

DOI: $10.15628 /$ holos. 2020.6366

\section{RESUMO}

O resumo do trabalho será precedido pelo subtítulo Resenha relativa à série de televisão norte-americana When We Rise, lançada em janeiro de 2017, que perpassa eventos históricos marcantes para o movimento LGBTQ+ nos Estados Unidos e que mostra como o preconceito e a homofobia vêm se institucionalizando nas ações da cultura, nas instituições e na política. Tendo em vista esse tempo, a série vem somar esforços ante a pertinência de discutir a presença do tema nas escolas, assim como alertar para o fato de que a sociedade tem boicotado, por ignorância e medo, a apresentação a ser feita de forma sistematizada, franca e despreconceituosa dentro das salas de aula na escola básica.

PALAVRAS-CHAVE:. Homofobia, Educação, Televisão, Minissérie, Diversidade sexual

\section{WHEN WE RISE AND THE FIGHT AGAINST HMOPHOBIA}

\begin{abstract}
When We Rise, a US television series, which was launched in January 2017, is a series of landmark events for the LGBTQ + movement in the United States that show how prejudice and homophobia have become institutionalized in the actions of culture, institutions and politics. In view of this time, the series comes
\end{abstract}

together with the pertinence of discussing the presence of the theme in schools, as well as alerting to the fact that society has boycotted, through ignorance and fear, the presentation to be made in a systematized way, frank and unprejudiced in classrooms in elementary school.

KEYWORDS: Homophobia, Education, TV, TV Series, Sexual diversity 
When We Rise ${ }^{1}$ é uma série/documentário de televisão que estreou este ano e que foi inspirada no livro de memórias de Cleve Jones (Guy Pearce), um ativista do movimento LGBTI nos Estados Unidos, na qual o grande e principal foco é a causa LGBTI².

Ali contam-se histórias de lutas pessoais e políticas deste grupo. Num atual momento no Brasil, em que, por meio de tanta dor e luta, vários direitos já adquiridos vêm sendo revogados diariamente, esta série se mostra pertinente e expõe, de maneira bastante humana a difícil, a realidade de muitos destes indivíduos e a sua busca por direitos civis fundamentais que a sociedade tanto ignora. Consegue-se perceber os privilégios de um grupo (heterossexual) em relação às privações do outro, a heteronormatividade excludente e a apatia de um governo preconceituoso.

Apesar de mostrar vários desafios de movimentos distintos, como o feminista, a patologização da homossexualidade e a epidemia da AIDS que foi e de certo modo ainda continua sendo usada para deslegitimar e até marginalizar homossexuais em nossa sociedade, atentaremos aqui para a institucionalização da homofobia. Aqui, por homofobia, entendesse o medo, aversão, descrédito e ódio aos gays, lésbicas, bissexuais, travestis e transexuais ${ }^{3}$.

Assim como na série When we rise (2017), comecemos pelo contexto histórico LGBT da época no Brasil. Fachinni4 afirma que durante o período da ditadura militar (1964-1985) grande parte dos anseios da sociedade sofreu severo controle, assim, os brasileiros foram às ruas pedindo reformas constitucionais. Ao realizarmos uma breve análise histórica sobre o povo brasileiro, torna-se nítido que desde os primórdios desta civilização uma característica nos é peculiar: nenhum filho teu foge à luta. As políticas públicas voltadas para a comunidade de gays, lésbicas, bissexuais, travestis, transexuais e transgêneros ganham força nos anos 80-90, uma vez que o surto do vírus HIV trouxe à tona uma realidade dantes velada em nossa sociedade 4 .

Surge posteriormente também a necessidade de incluir aspectos de direitos humanos voltados para estas questões, uma vez que medidas especiais precisavam ser construídas e solidificadas paulatinamente junto ao Congresso Brasileiro para trazer melhor qualidade de vida para esta comunidade. Em 1996 foram incluídos no Plano Nacional de Direitos Humanos, o qual foi o primeiro documento oficial da República Federativa do Brasil a citar o gênero homoafetivo. Em 2003 receberam o devido foco preventivo na campanha "Brasil sem Homofobia" 5.

Em 2008 aconteceu a conferência Nacional LGBT que reuniu cerca de 10 mil participantes contando com a presença do então presidente Luís Inácio Lula da Silva, onde, pela primeira vez na história da luta dos direitos civis LGBT, o representante de uma nação ouviu suas petições5.

$\mathrm{Na}$ série vemos o posicionamento da medicina e psicologia antes e depois dos movimentos homossexuais em todo o mundo. Em 1973 a Associação Americana de Psiquiatria deixou de categorizar a homossexualidade como distúrbio psicológico. Já no Brasil, o Conselho Federal de Medicina deixou de categorizar também como doença apenas em 1985, e o Conselho Federal de Psicologia somente em 1999. Sob os processos recebidos pela Associação Brasileira de Gays, Lésbicas e Travestis - ABGLT - também cedeu e removeu a homossexualidade do rol de transtornos mentais ${ }^{6}$.

De 1974 - ano em que se passa a série - até os dias atuais, o cenário LGBT no Brasil, e no mundo, encontra-se cada vez mais instável. Direitos foram conquistados e reconhecidos nos últimos 43 anos, visibilidade foi alcançada, mas nunca o preço foi tão alto. Segundo relatórios do 
Grupo Gay da Bahia (GGB) em 2016 foram registradas 344 mortes de indivíduos LGBT no Brasil. Mortes de caráter homofóbicas. No entanto, o dado conclusivo desta análise estatística revela que as mortes estão aumentando desde que o GGB passou a monitorar as estatísticas de obituário LGBT no Brasil em 20087.

Uma das falas do personagem principal da série, o homossexual ativista LGBT Cleve Jones (Guy Pearce) é sobre o fato de ter medo de um dia acordar e ver destruído tudo aquilo porque lutaram. Hoje vemos que um dos medos de Cleve Jones pode estar prestes a se concretizar. Ainda estão de pé todas as leis aprovadas que garantem direitos iguais para os LGBT, porém, houve um levante também daqueles que rejeitam e desprezam a homossexualidade, e por ela sentiram-se inseguros quanto ao futuro da sociedade cuja normativa é heterossexual, algo como se uma anarquia gay viesse a se instalar ${ }^{8}$.

No Brasil este embate externo agravou-se a partir dos anos 90 quando a comunidade LGBT veio pedir por seus direitos como: políticas públicas que assegurassem seus direitos por saúde, redução da violência, penas para homofóbicos, reconhecimento da união entre pessoas do mesmo sexo, distribuição dos kits educacionais sobre a comunidade LGBT em escolas, dentre outras situações. Assim, em Estados como a Bahia (32 mortos em 2016), Rio de Janeiro (30 mortos em 2016) e São Paulo (49 mortos em 2016) a situação vista é de guerra ${ }^{7}$.

Segundo Souza e Helal $^{9}$ a questão de saúde pública para LGBTs abarca uma série de aspectos que reverberam o tamanho da violação diária de seus direitos como cidadãos devido a sua orientação sexual:

[...] o que parece indicar como a homofobia se faz presente no desejo de destruição (física, moral ou psicológica) não apenas da pessoa específica das vítimas, mas também do que elas representam - ou seja, da existência de pessoas LGBT em geral.

Outra situação de embate constante, e muito atual, se refere as visões de caráter religioso-políticas, visto que ainda hoje a homossexualidade é considerada por muitos como o mais torpe, sujo e desonesto pecado ${ }^{8}$.

O personagem Cleve Jones (Guy Pearce) em dado momento mostra a soberania da igreja sobre a política local, uma vez que gays eram espancados e perseguidos pela polícia a comando desta hierarquia vigente (igreja - política). Este dado é relatado na série e reafirmado por Correa10, onde o comportamento homossexual antes de ser um assunto de caráter científico é um assunto cuja influência política é imensa em nossa sociedade (igreja - normalidade vigente).

Trata-se de uma instituição antiga que desde a idade Média vem construindo um cenário religioso-político amplamente aceito em nossa sociedade hoje, pois os contrários as normativas católicas sofriam as consequências da Santa Inquisição - encontrar e destruir ${ }^{10}$. Tornou-se então parte do conjunto de esquemas mentais coletivos necessários para uma rotina saudável obedecer sem questionamentos, aos contrários, hereges, a fogueira.

Em se tratando dos embates internos, os grupos de interesses fundamentais para os LGBTs seccionaram-se dentro de suas categorias transversais, tornando-se cada vez menores e mais específicos, quebrando uma cadeia de forças a qual demorou a ser construída. Logo os 
embates externos não eram a única preocupação. Durante a série, a personagem Roma Guy (Mary-Louise Parker) chega a Boston, em 1974, e depara-se com um grupo de feministas que rejeitam a coexistência com lésbicas em seu grupo, as quais foram expulsas assim que se revelaram. A notícia deixa a personagem sem orientação, pois sua ida aquele destino partiu da premissa que juntas lutariam por direitos igualitários para todas as mulheres, atitude esta que viria futuramente a expandir-se no Brasil também.

As colegas feministas de Roma (Mary-Louise Parker) em Boston percebem então que além de algumas integrantes do movimento se sentirem incomodadas com a presença da comunidade lésbica, os congressistas, com os quais elas deliberavam sobre seus direitos, também o estavam, então as mesmas precisaram tomar medidas que as afastariam da ideia principal de sua causa - mulheres por mulheres. O que ocorreu foi descrito por Fachinni ${ }^{5}$ : os grupos passaram a organizar-se melhor e comportar-se de forma mais parecida com a de ONGs. Desta forma foi concedida a elas o poder de deliberar com parlamentares, mas distanciaram-se de sua base.

Foge ao raciocínio dos considerados normais, que nossas singularidades integram um todo. Não se deve contribuir para permanência de um Estado segregado, uma vez que nunca foi uma característica nossa a homogeneidade para buscá-la cegamente, com perseguição e morte aos diferentes, nossas raízes étnicas são belos exemplos de pluralidades.

Em inúmeros momentos, percebeu-se nas falas de alguns personagens e em imagens de arquivo reais, manifestações homofóbicas praticadas por indivíduos que deveriam discutir, promover e assegurar condições básicas de bem-estar e saúde para todos. Muito claramente, vemos essa institucionalização homofóbica na política e no modo como ela tem-se dado principalmente nos dias atuais, de maneira que, assim como em When We Rise (2017), vários dos direitos e demandas já adquiridos que conhecemos hoje pelo grupo LGBTI e que se mostram evidentemente necessários, vem sendo anulados e/ou não sendo aprovados ou efetivados de maneira contundente. Este é o caso da lei orgânica de Manaus 43911, idealizada por um político que, bem mais em sua condição de pastor, mostrou considerar a discussão sobre homofobia, que envolvem a realidade do grupo LGBTI, machismo e que tratam de gênero desnecessárias para o ensino fundamental escolar resolvendo assim criar uma lei para proibi-la nas escolas municipais. Uma mordaça aos professores dos ensinos fundamental e médio.

Os discursos que tentam impedir tais debates sobre, e acerca da legitimidade de direitos fundamentais desse grupo são, assim como os vistos na série, sempre os mesmos: proteger e zelar pela família, a infância e a construção de valores mais pertinentes para essa fase da vida, mascarando assim seus preconceitos.

Enquanto instituição social, a escola é portanto, espaço privilegiado para uma discussão elevada. É claro que este sempre foi e ainda é um assunto bastante delicado e que carrega grandes tensões, contudo entre vários discursos, os de alguns profissionais da educação se mostram preocupantes em demasia. A falta de preparo, o medo, as crenças/posicionamentos individuais e principalmente a recusa em tratar este tema são empecilhos para o trabalho pedagógico de maneira integral, o que acaba por transformar o trabalho numa redundância limitada apenas ao aspecto biológico e informativo. Ameaçar profissionais que o tentam de maneira mais profunda, como tem feito nossos políticos, parece-nos criminoso. A homofobia mostra-se com grandes atenuantes na escola, sendo percebidas tanto no próprio corpo docente, 
quanto discente. Desde bem pequenos nossos alunos são reprimidos por determinados comportamentos ligados direta ou indiretamente, consciente ou não à sexualidade, por seus professores e à medida que crescem reproduzem os mesmos comportamentos preconceituosos. Nossas instituições sociais, principalmente as que legitimam direitos, produzem conhecimentos e asseguram bem-estar ainda estão bem distantes de estar promover igualdade e respeito à todos.

When We Rise (2017) expõe claramente a negligência histórica do Estado para com o grupo LGBTI e o quanto os jovens de antes tiveram que lutar para abrir passagem para os direitos civis atuais que conhecemos. Este é definitivamente um jogo de poder, como nos mostra Foucault ${ }^{12}$ "Com respeito ao sexo, o poder jamais estabelece relação que não seja de modo negativo: rejeição, exclusão, recusa, barragem ou, ainda, ocultação e mascaramento". (p. 91). Nesse sentido, e como bem mostra a série ao retratar o período de quando a epidemia da Aids começou, vimos um Estado omisso (tanto nos EUA quanto em todo mundo) que só demonstrou preocupação quando suas mulheres e crianças começaram a ser infectados, ou seja, quando o grupo primário de ataque não era mais o único afetado pele epidemia.

Nossa sociedade heteronormativa demonstra que seu enorme preconceito vem exatamente do medo. A desinformação e a falta de empatia à que somos tomados fazem com que fiquemos temerosos, mas isso não nos exime de culpa pela dor e falta de bem-estar deste grupo.

A luta neste momento, vem sendo a abertura de espaço para discussões de gênero de forma sistematizada e por que não na escola? A educação precisa abranger a sociedade em sua totalidade e na busca pelo desenvolvimento pleno e sadio de nossos cidadãos, nos professores devemos fazê-lo integralmente e sim, definitivamente dá para fazê-lo desde a educação infantil.

Este seriado, e tantas outras películas produzem o que Deschamps e Honorato ${ }^{13}$ chamam de Cinematerapia Reflexiva, reverberando socialmente e nos levando a debates importantes para os dias atuais. Ao evidenciar tantas histórias que nós até já conhecemos e por tantas vezes ignoramos, o seriado deixa explicito que por mais direitos que este grupo e incluímos aqui também outras "minorias" tenham e venham a alcançar, sempre terá alguém(s) tentando derrubá-los.

Então que fazer com tantas demandas extremamente especificadas? Cabe a nós o entendimento que nunca será possível atender massivamente a tantas especificidades, porém é possível realizar o levantamento das causas comuns a todos, e as que são de requerimento imediato, reunir as forças destes grupos transversalizados e lutar por aprovações de ementas, resoluções e leis que tragam uma qualidade de vida melhor e reconhecimento de direitos plenos a todo o cidadão brasileiro, tornando-nos uma comunidade cuja soberania seja inclusiva e não separatista. 


\section{REREFÊNCIAS}

1 When We Rise. EUA: HBO; 2017.

2 Gonzaga, R, When We Rise - Minissérie é a bíblia LGBT moderna - e todo mundo deveria assistir [Internet], 2017 [acesso em 09 maio 2017]. Disponível em: https://omelete.uol.com.br/series-tv/artigo/when-we-rise-e-a-biblia-moderna-lgbt-e-omundo-deveria-assistir-a-missiserie/

3 Marreto C, Filho F, Bessa J. Homofobia no contexto escola. Fazendo Gênero 9 [Internet], 2010 [acesso em 12 maio 2017]. Disponível em: http://www.fazendogenero.ufsc.br/9/resources/anais/1277952282_ARQUIVO_FG9Teixeira_Marretto.pdf

4 Fachinni, R. Histórico da luta de LGBT no Brasil. Site Conselho Regional de Psicologia SP, [Internet], 2017 [acesso em 09 maio 2017] Disponível em: http://www.crpsp.org.br/portal/comunicacao/cadernos_tematicos/11/frames/fr_historico.a $\operatorname{spx}$

5 Fachinni, R. Entre compassos e descompassos: um olhar para o "campo" e para a "arena" do movimento LGBT brasileiro. Rev. Bagoas - estudos gays: gêneros e sexualidades, v.4, n. 5, 2009.

6 Conselho Federal de Psicologia. Resolução n. 001. (1999, 22 de março). Estabelece normas de atuação para os psicólogos em relação à questão da Orientação Sexual. [Internet], 2017 [acesso em 18 maio 2017]. Disponível em: http://pol.org.br/legislacao/pdf/resolucao1999_1.pdf

7 Ayer F, Bottrel F. Brasil é país que mais mata travestis e transexuais. Estado de Minas [Internet], 2017 [acesso em 10 maio 2017].

Disponível em: http://www.em.com.br/app/noticia/especiais/dandara/2017/03/09/noticiaespecial-dandara,852965/brasil-e-pais-que-mais-mata-travestis-e-transexuais.shtml

8 OLIVOliveira C E de, Alberto M F P. Violência Homofóbica e políticas públicas de direitos humanos. v.9, n. 13, [Internet], 2015 [acesso em 11 maio 2017]. Disponível em: https://periodicos.ufrn.br/bagoas/article/view/9881/6992

9 Souza, M B C A de, Helal, D H. Política Nacional de Saúde Integral de Lésbicas, Gays, Bissexuais, Travestis e Transexuais: análise descritiva e utilização de dados secundários para pesquisa e prática. Rev. Bagoas - estudos gays: gêneros e sexualidades, v. 9, n. 13, [Internet], 2015 [acesso em 10 maio 2017]. Disponível em: https://periodicos.ufrn.br/bagoas/article/view/9656/6897 
10 Corrêa S. O Percurso Global dos direitos sexuais. Rev. Bagoas - estudos gays: gêneros e sexualidades, v.4, n. 5, [Internet], 2009 [acesso em 12 maio 2017]. Disponível em: https://periodicos.ufrn.br/bagoas/article/view/2294/1727

11 MANAUS, LEI N. 439, D.O.L.M. 07.03.2017 - N. 639, Ano IV. Manaus: AM, 3 de Março de 2017

12 Foucault, M. História da Sexualidade: a vontade de saber. Ed. Paz\&Terra, 2017.

13 Deschamps D, Honorato E J S H. Cinematerapia: Entendendo Conflitos. Rio de Janeiro: Ed. Multifoco, 2009. 